medgen 2018 · 30:410-421

https://doi.org/10.1007/s11825-018-0215-1

Online publiziert:22. November 2018

(c) Der/die Autor(en) 2018

CrossMark

\author{
Julia Hoefele ${ }^{1}$ Bodo B. Beck ${ }^{2}$ Lutz T. Weber ${ }^{3}$ Paul Brinkkötter ${ }^{4}$ \\ ${ }^{1}$ Institut für Humangenetik, Klinikum rechts der Isar, Technische Universität München, München, \\ Deutschland \\ ${ }^{2}$ Institut für Humangenetik, Uniklinik Köln, Köln, Deutschland \\ ${ }^{3}$ Klinik und Poliklinik für Kinder- und Jugendmedizin, Uniklinik Köln, Köln, Deutschland \\ ${ }^{4}$ Klinik II für Innere Medizin, Uniklinik Köln, Köln, Deutschland
}

\title{
Steroid-resistentes nephrotisches Syndrom
}

\section{Einleitung}

Sowohl im Kindes- wie auch im Erwachsenenalter ist das nephrotische Syndrom (NS) durch die Kombination aus großer Proteinurie $\left(>1 \mathrm{~g} / \mathrm{m}^{2}\right.$ Körperoberfläche $[\mathrm{KOF}] \times \mathrm{Tag}$ bzw. $>40 \mathrm{mg} / \mathrm{m}^{2} / \mathrm{h}$ und $\mathrm{Hy}$ palbuminämie $[<2,5 \mathrm{~g} / \mathrm{dl}])$ definiert. Die Diagnose wird primär klinisch unter Zuhilfenahme laborbiochemischer Befunde gestellt. Die klassische Trias aus Proteinurie, Ödemen und Nierenkrankheit wurde bereits 1830 von Richard Bright beschrieben.

Das primäre NS im Kindesalter zählt mit ca. 250-300 Neuerkrankungen/Jahr (Inzidenz 2-3:10 $0^{5}$, Prävalenz ca. 16:10 $)$ in Deutschland zwar zu den seltenen Erkrankungen, stellt aber eine relevante Gruppe pädiatrischer Nierenerkrankungen dar. Den größten Anteil an dieser heterogenen Gruppe machen mit ca. $80 \%$ die primär idiopathischen Formen des NS aus. Hier liegt der Erkrankungsgipfel zwischen dem 2. und 6. Lebensjahr, und die Patienten zeigen oft einen plötzlichen Erkrankungsbeginn mit Assoziation zu Infekten. Bei diesen Patienten besteht in aller Regel ein steroid-sensitives nephrotisches Syndrom (SSNS). Das NS kann einmalig auftreten oder es können im Erkrankungsverlauf mehrere bis häufige (>4/Jahr) Rezidive des NS auftreten. In der Nierenbiopsie zeigen diese Patienten i.d.R. glomeruläre Minimalläsionen (MCD). Mit den seltenen Ausnahmen von EMP2, KANK1 und KANK2 sind bisher keine Gene für das SSNS beschrieben $[1,2]$. Weniger als $20 \%$ der Fälle stellen Patienten mit einem SRNS dar, bei denen in der Nierenbiopsie häufig als histopathologisches Korrelat eine fokal-segmentale Glomerulosklerose (FSGS) nachgewiesen werden kann. Diese Erkrankungsgruppe zeigt eine altersabhängige, mitunter sehr ausgeprägte genetische Heterogenität, auf die weiter im Hauptteil des Manuskripts eingegangen werden soll.

Im Unterschied zu Kindern tritt das NS (Gesamtinzidenz ca. 3-5:10 ) bei erwachsenen Patienten häufig sekundär infolge anderer Begleiterkrankungen wie z.B. Diabetes mellitus Typ II, Amyloidose, arterielle Hypertonie, Malignome, Infektionen oder nach Einnahme von Medikamenten auf [3-10]. Primär idiopathische Verlaufsformen ohne begleitende Komorbiditäten sind hier eher selten (Inzidenz ca. 3:10 ${ }^{6}$ in Deutschland) [11], die Zahl primär genetischer Formen ist vermutlich geringer als in der pädiatrischen Vergleichsgruppe, aber systematische genetische Studien zu SRNS/ FSGS bei Erwachsenen fehlen, sodass genetische Formen hier möglicherweise untererfasst sind. Im Gegensatz zu Kindern erhalten erwachsene Patienten aufgrund der vielfältigen sekundären Ursachen i.d. R. schon bei Erstmanifestation eine Nierenbiopsie. Die glomerulären Minimalläsionen (engl. „minimal change disease", MCD), die membranöse Glomerulonephritis (MGN), die mesangioproliferative GN (MPGN) und die FSGS stellen führende histopathologische Befunde eines primären NS dar und gehen mit relevanten Risiken für die Entwicklung einer chronischen Niereninsuffizienz und eines terminalen
Nierenversagens einher. Die Verteilung unterliegt ethnischen Unterschieden, bei Erwachsenen in Deutschland reicht sie von ca. 3,2 (MCD) über 11,2 (FSGS) bis 20,9 pro 1 Mio. Einwohner für die MPGN [11]. Auf die MGN und die MPGN soll hier nicht weiter eingegangen werden, da für diese bis auf die extrem seltene Ausnahme der kongenitalen membranösen Nephropathie (MIM \#614692) derzeit keine klar monogenen Formen bekannt sind. Mit Identifikation der G1- (p.Ser342Gly und p.Ile384Met) und G2-Allele (,in-frame" Deletion p.388_89delNY) im APOL1-Gen konnte erstmals ein genetischer Risikofaktor für die höhere FSGS-Rate unter afroamerikanischen Patienten gefunden werden [12].

Die Therapie erfolgt im deutschsprachigen Raum standardisiert nach den Empfehlungen der Gesellschaft für Pädiatrische Nephrologie (GPN) [13] bzw. der KDIGO-Guidelines (https://kdigo. org). Dieses standardisierte Vorgehen dient u.a. der weiteren Einteilung der Erkrankung und der Planung fortführender Therapien. Während ungefähr 80-90 \% der pädiatrischen Patienten bei der Erstmanifestation primär auf eine Glukokortikoidgabe ansprechen, zeigen sich bei Erwachsenen deutlich schlechtere Ansprechraten, und bereits eine partielle Remission gilt als Therapieerfolg [14-17]. Auch erwachsene Patienten mit einer MCD sprechen in der Regel gut auf Glukokortikoide an, während FSGSPatienten häufig eine Steroidresistenz aufweisen. 
Tab. 1 Klassifikation des nephrotischen Syndroms im Kindesalter (aus [21])

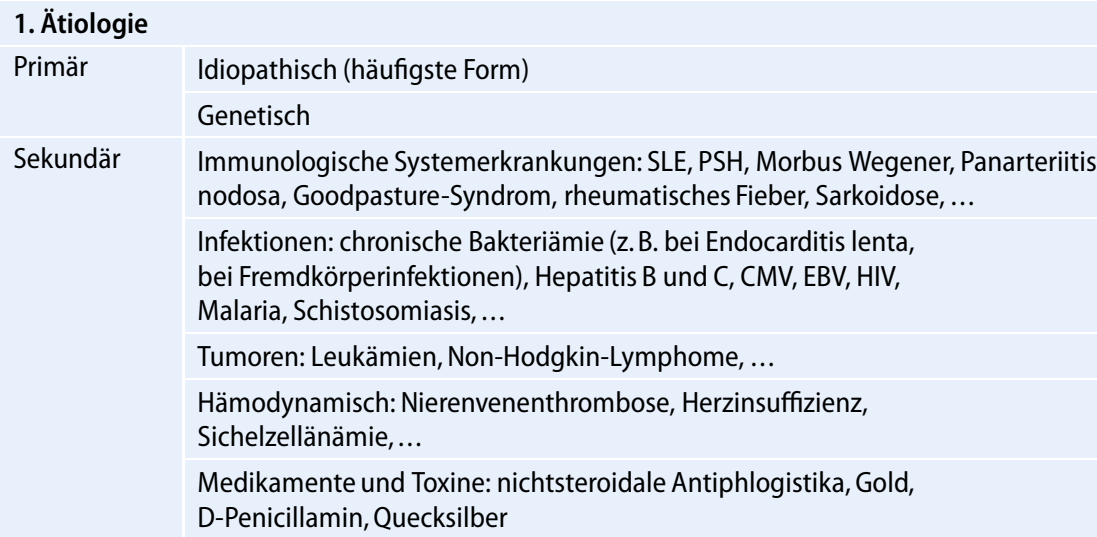

\section{Alter bei Erstmanifestation}

\begin{tabular}{l|l}
\hline 0-3 Monate & Kongenitales nephrotisches Syndrom \\
\hline 4-12 Monate & Infantiles nephrotisches Syndrom \\
\hline 1-10 Jahre & Häufig: Minimal-Change-Glomerulonephritis \\
\hline 10-18 Jahre & -
\end{tabular}

3. Ansprechen auf Glukokortikoide (Idiopathisches nephrotisches Syndrom)

SSNS Remission nach $60 \mathrm{mg} / \mathrm{m}^{2} \mathrm{KOF} \times$ Tag Prednison innerhalb von 4 Wochen

In Abhängigkeit der Rezidivhäufigkeit wird das SSNS weiter unterteilt:

Infrequent relapser: $<4$ Rezidive innerhalb von 12 Monaten oder $<2$ Rezidive innerhalb von 6 Monaten nach Erstmanifestation

FRNS: <4 Rezidive innerhalb von 12 Monaten oder <2 Rezidive innerhalb von 6 Monaten nach Erstmanifestation

SDNS: Mindestens 2 aufeinanderfolgende Rezidive unter der alternierenden Therapie mit Prednison oder innerhalb von 14 Tagen nach Therapieende

SRNS Keine Remission nach $60 \mathrm{mg} / \mathrm{m}^{2} \mathrm{KOF} \times$ Tag Prednison über 4 Wochen

\section{Histologie}

Minimal-Change-Glomerulonephritis

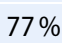

FSGS

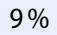

Diffuse mesangiale Sklerose

$2 \%$

Mesangiale proliferatltive Glomerulonephritis

$3 \%$

Membranöse Glomerulonephritis

$1 \%$

Membranoproliferative Glomerulonephritis

$6 \%$

Andere, nicht klassifiziert

$2 \%$

SLE systemischer Lupus erythematodes, PSH Purpura Schoenlein-Henoch, CMV Zytomegalievirus, EBV Ebstein-Barr-Virus, HIV humanes Immundefizienzvirus, KOF Körperoberfläche, SSNS steroid-sensibles nephrotisches Syndrom, FRNS "frequent relapser", SDNS steroid-abhängiges nephrotisches Syndrom, SRNS steroid-resistentes nephrotisches Syndrom, FSGS fokal-segmentale Glomerulosklerose

Nachteilig für die Einteilung der Patienten ist, dass in der Literatur keine einheitliche Definition für das SRNS existiert. Nach der GPN und der American Academy of Pediatrics ist ein Kind mit NS als steroid-resistent einzustufen, wenn nach 4-wöchiger Therapie mit $60 \mathrm{mg}$ Prednison $/ \mathrm{m}^{2} \mathrm{KOF} \times$ Tag keine
Remission erfolgt ist $[13,18]$. Jedoch ist gelegentlich ein Ansprechen erst nach längerer oder intensivierter Gabe von Glukokortikoiden möglich. Ähnliches gilt für Erwachsene: Hier zeigt sich in der Regel eine Reduktion der Proteinurie innerhalb der ersten 8-12 Wochen nach Therapiebeginn. Patienten, die während der Reduktion der Glukokortikoide bzw. innerhalb von 2 Monaten nach Absetzen der Glukokortikoidtherapie erneut erkranken, gelten als steroid-abhängig (SDNS). Patienten, die nur einen minimalen bzw. keinen Rückgang der Proteinurie nach 12- bis16-wöchiger Therapie aufweisen, gelten als steroidresistent.

Wichtig für Therapie und Prognose des NS ist also die Klassifikation nach Alter bei Erstmanifestation, Ansprechen auf die Therapie mit Glukokortikoiden (steroid-sensitiv versus steroidresistent), histologischen Befunden und letztendlich (molekulare) Ätiologie der Erkrankung (• Tab. 1 und 2).

\section{Symptomatik des SRNS im Kindes- und Erwachsenenalter}

Grundsätzlich unterscheidet sich die klinische Symptomatik bei Erstmanifestation des SRNS nicht von der des SSNS weder im Kindes- noch im Erwachsenenalter. Klinisch führend sind die ggf. sehr rasch auftretenden Ödeme, die sich insbesondere als „renale“ Ödeme an den Augenlidern ( $\bullet$ Abb. 1a), aber auch an den abhängigen Körperpartien (• Abb. 1d, e) oder bei schweren Verläufen als Aszites (siehe - Abb. 1c) zeigen. Der Nachweis einer nephrotischen Proteinurie bestätigt die Verdachtsdiagnose. Insbesondere Lidschwellungen werden zu Erkrankungsbeginn nicht selten als allergische Reaktion fehlgedeutet.

Folgende akute Komplikationen in der Phase der nephrotischen Proteinurie sind zu beachten:

1. Thromboembolien: Diese zeigen sich oft als Sinusvenenthrombose. Eine entsprechende zerebrale Bildgebung sollte unverzüglich bei Kopfschmerzen, Vigilanzstörungen bzw. Hirndruckzeichen durchgeführt werden. Die Inzidenz thromboembolischer Komplikationen wird mit 2-5\% angegeben [19]. Ursächlich ist die Kombination folgender Faktoren: Verlust antithrombotischer Faktoren über den Urin, Hypovolämie und erhöhte Blutviskosität, Immobilisierung, Thrombozytose und erhöhte Plättchenaggregabilität. 
2. Infektionen: Ursächlich sind eine Verminderung der humoralen und zellulären Immunität sowie die immunsuppressive Therapie und die Ansammlung seröser Flüssigkeiten (Aszites, Pleuraergüsse). Obgleich bakterielle Infektionen in der Akutphase nicht sehr häufig sind, können sie sehr schwerwiegend sein: Pneumonie, Meningitis, Sepsis, Phlegmonen, Empyeme, Peritonitiden. Häufige Erreger sind Staphylokokken und Streptococcus pneumoniae.

3. Lungenödem: Insbesondere bei $\mathrm{Pa}$ tienten mit einem oligurischen Nierenversagen und schweren, therapierefraktären Ödemen besteht das Risiko für die Entstehung eines Lungenödems. Cave: In dieser Situation können Albumininfusionen bei unzureichender Ausscheidung zu einer Flüssigkeitsumverteilung in die Lungenstrombahn führen.

4. Hypothyreose: Diese ist passager und durch den Verlust von thyroxinbindendem Globulin zu erklären. $\mathrm{T}_{4}$ und $\mathrm{T}_{3}$-Spiegel sind erniedrigt, aber $\mathrm{FT}_{4}$ und TSH sind normalerweise normal, sodass diese Patienten als euthyreot angesehen werden. Eine Indikation zur Substitutionstherapie liegt in den meisten Fällen nicht vor, kann aber bei Patienten mit lang andauernder Proteinurie und ausgeprägter Hypothyreose gegeben sein.

5. Dyslipidämie: Gesteigerte hepatische Synthese und veränderter Metabolismus führen $\mathrm{zu}$ dieser passageren Störung, die sich nach Erlangen der Remission zurückbildet. Eine Therapieindikation ergibt sich allenfalls bei Persistenz im Rahmen eines Fortbestehens der großen Proteinurie bei Steroidresistenz oder nur partiellem Therapieansprechen wegen des langfristig erhöhten kardiovaskulären Risikos. Dennoch empfiehlt die American Academy of Pediatrics bei Kindern mit idiopathischem NS eine Low-fat-Diät.

Eine Einschränkung der Nierenfunktion ist in der akuten Phase des idiopathischen NS eher selten zu beobachten, gelegentlich wird aber durch eine intravasale $\mathrm{Hy}$ -

medgen 2018·30:410-421 https://doi.org/10.1007/s11825-018-0215-1

(c) Der/die Autor(en) 2018

\section{J. Hoefele • B. B. Beck · L. T. Weber · P. Brinkkötter \\ Steroid-resistentes nephrotisches Syndrom}

\section{Zusammenfassung}

Das steroid-resistente nephrotische Syndrom (SRNS) mit dem histomorphologischen Korrelat der fokal-segmentalen Glomerulosklerose (FSGS) stellt eine bedeutende Ursache für eine terminale Niereninsuffizienz im Kindesalter, aber auch bei erwachsenen Patienten dar. Das Erkrankungsspektrum zeichnet sich durch eine große genetische Heterogenität aus, wobei auch nicht genetische Ursachen bei der FSGS beobachtet werden. Die genetische Grundlage des SRNS/FSGS-Komplexes ist v.a. für ältere Kinder/Jugendliche und Erwachsene bisher noch unzureichend verstanden. Die eindeutige Abgrenzung genetischer SRNS/FSGS-Ursachen ist unerlässlich, da sich bereits heute hieraus eine Vielzahl an klinischen Implikationen ergeben. Die Identifikation unbekannter Erkrankungsallele oder Erkrankungsgene kann zudem Erkenntnisse bringen, die ein gänzlich neues Verständnis der Pathomechanismen ermöglichen. Durch umfassende genetische Untersuchungen besteht die Möglichkeit, die ungelöste genetische Basis der Rekurrenz der FSGS-Erkrankung bei bislang Variantennegativen Patienten zu finden.

Schlüsselwörter

Steroid-resistentes nephrotisches Syndrom . SRNS · SSNS · FSGS · Mutationsanalyse

\section{Steroid-resistent nephrotic syndrome}

\section{Abstract}

Steroid-resistant nephrotic syndrome (SRNS), together with the histomorphological correlate focal segmental glomerulosclerosis (FSGS), is a leading cause of end-stage renal disease (ESRD) in older children, adolescents, and adults. The disease spectrum is characterized by great genetic heterogeneity, but nongenetic causes are also observed in FSGS. The genetic basis of SRNS/FSGS in adolescents and adults is far from being completely understood. Reliable discrimination of the genetic causes of SRNS/FSGS is imperative, as there are already numerous clinical implications. The identification of new disease-causing alleles and genes will enhance our understanding of the underlying pathomechanisms. Using extensive genetic testing there is the possibility of finding the unresolved genetic basis for the recurrence of FSGS in patients without a genetic variant.

\section{Keywords}

Steroid-resistant nephrotic syndrome - SRNS . SSNS · FSGS · Mutational analysis povolämie ein prärenales Nierenversagen ausgelöst. Bei den sekundären NS finden sich Nierenfunktionseinschränkungen im Rahmen der Grunderkrankung wesentlich häufiger.

Im Gegensatz zum SSNS weisen 50-80 \% der Patienten mit SRNS eine Mikrohämaturie (nephritisch/nephrotisches Syndrom) auf, eine Makrohämaturie hingegen ist selten und sollte weiterführende Diagnostik zum Ausschluss anderer Ursachen nach sich ziehen. Anders als für das SSNS dargestellt, entwickelt ein Großteil der SRNS-Patienten eine progrediente chronische Niereninsuffizienz. Dies gilt insbesondere für Patienten mit kongenitaler oder früher Manifestation einer hereditären Form der Erkrankung, hier können je nach Studie und Zusam- mensetzung der Kohorte die Patienten in bis zu $83 \%$ der Fälle eine terminale Niereninsuffizienz entwickeln [20]. Im Rahmen des Fortschreitens der Niereninsuffizienz sowie bedingt durch eine Überwässerung weisen viele Patienten einen arteriellen Hypertonus auf. Gelegentlich steht auch der massive arterielle Hypertonus direkt im Vordergrund (z. B. WT1-assoziierte Formen).

SRNS-Patienten ohne Nachweis einer hereditären Form der Erkrankung hingegen haben, wenn sie auf eine Therapie mit Cyclosporin A ansprechen, eine deutlich bessere Prognose (bis zu 98 \% 10-JahresNierenüberleben) [21]. 


\begin{tabular}{|c|c|c|c|c|c|c|c|c|}
\hline Gen & $\begin{array}{l}\text { Gen } \\
\text { MIM \# }\end{array}$ & Protein & Genort & $\begin{array}{l}\text { Verer- } \\
\text { bungs- } \\
\text { modus }\end{array}$ & Phänotyp & $\begin{array}{l}\text { Phänotyp } \\
\text { MIM \# } \\
\text { (sofern } \\
\text { vorhanden) }\end{array}$ & $\begin{array}{l}\text { Nieren- } \\
\text { histologie }\end{array}$ & $\begin{array}{l}\text { Häufig- } \\
\text { keit }\end{array}$ \\
\hline \multicolumn{9}{|c|}{ Schlitzdiaphragma-assoziierte Proteine } \\
\hline$C D 2 A P$ & 604241 & $\begin{array}{l}\text { CD2-associated } \\
\text { protein }\end{array}$ & $6 \mathrm{p} 12$ & $\begin{array}{l}\text { AR, (AD } \\
\text { Risikofaktor) }\end{array}$ & SRNS (early onset) & 607832 & FSGS & Selten \\
\hline NPHS1 & 602716 & Nephrin & $19 q 13.12$ & AR & $\begin{array}{l}\text { CNS (finnischer Typ) bis SRNS } \\
\text { (early onset) }\end{array}$ & 256300 & $\begin{array}{l}\text { Nicht spezi- } \\
\text { fisch, FSGS, } \\
\text { MC }\end{array}$ & Häufig \\
\hline NPHS2 & 604766 & Podocin & $1 \mathrm{q} 25.2$ & AR & $\begin{array}{l}\text { CNS bis SRNS (variabel: early } \\
\text { und late onset; late onset spe- } \\
\text { zifische C-terminale Varianten } \\
\text { und C-terminale Varianten in } \\
\text { trans mit p.Arg229GIn) }\end{array}$ & 600995 & FSGS, MC & Häufig \\
\hline PLCE1 & 608414 & $\begin{array}{l}\text { Phospholipase } \\
\text { C epsilon } 1\end{array}$ & $10 q 23.33$ & AR & CNS bis SRNS (early onset) & 610725 & DMS, FSGS & Moderat \\
\hline TRPC6 & 603652 & $\begin{array}{l}\text { Transient receptor } \\
\text { potential channel } \\
\text { C6 }\end{array}$ & $11 q 22.1$ & $A D$ & SRNS (late onset) & 603965 & FSGS & Moderat \\
\hline \multicolumn{9}{|c|}{ Nukleäre Proteine und Transkriptionsfaktoren } \\
\hline$L M X 1 B$ & 602575 & $\begin{array}{l}\text { LIM homeobox } \\
\text { transcription } \\
\text { factor } 1 \beta\end{array}$ & $9 q 33.3$ & $A D$ & $\begin{array}{l}\text { SRNS isoliert (variabel early bis } \\
\text { late onset) oder syndromal: } \\
\text { Nagel-Patella-Syndrom (NPS) }\end{array}$ & 161200 & FSGS & Moderat \\
\hline NUP93 & 614351 & $\begin{array}{l}\text { Nuclear pore } \\
\text { complex protein } \\
93\end{array}$ & $16 q 13$ & $A R$ & SRNS (early onset) & 616892 & FSGS & $\begin{array}{l}\text { Selten- } \\
\text { moderat }\end{array}$ \\
\hline NUP107 & 607617 & $\begin{array}{l}\text { Nuclear pore } \\
\text { complex protein } \\
107\end{array}$ & $12 q 15$ & $\mathrm{AR}$ & SRNS (early onset) & 616730 & FSGS & $\begin{array}{l}\text { Selten- } \\
\text { moderat }\end{array}$ \\
\hline NUP205 & 614352 & $\begin{array}{l}\text { Nuclear pore } \\
\text { complex protein } \\
205\end{array}$ & $7 q 33$ & AR & SRNS & 616893 & FSGS & $\begin{array}{l}\text { Sehr } \\
\text { selten }\end{array}$ \\
\hline$P A X 2$ & 167409 & $\begin{array}{l}\text { Paired box prote- } \\
\text { in } 2\end{array}$ & $10 q 24.31$ & $A D$ & $\begin{array}{l}\text { SRNS isoliert (variabel bis late } \\
\text { onset) oder syndromal: Papil- } \\
\text { lorenales Syndrom/Renales } \\
\text { Kolobom-Syndrom (RCS) }\end{array}$ & $\begin{array}{l}616002 \text { bzw. } \\
120330\end{array}$ & FSGS & Moderat \\
\hline SMARCAL1 & 606622 & $\begin{array}{l}\text { SMARCA-like } \\
\text { protein }\end{array}$ & $2 q 35$ & AR & $\begin{array}{l}\text { Immuno-ossäre Dysplasie nach } \\
\text { Schimke: syndromales SRNS } \\
\text { (early onset): Skelett, Immun- } \\
\text { defizienz }\end{array}$ & 242900 & FSGS & Moderat \\
\hline WDR73 & 616144 & $\begin{array}{l}\text { WD repeat do- } \\
\text { main } 73\end{array}$ & $15 q 25.2$ & $\mathrm{AR}$ & $\begin{array}{l}\text { Galloway-Mowat-Syndrom Typ } \\
\text { 1: syndromales SRNS (early } \\
\text { onset), Mikrozephalie, ZNS-An- } \\
\text { omalien, faziale Dysmorphien }\end{array}$ & 251300 & FSGS, DMS & Selten \\
\hline LAGE3 & 300060 & $\begin{array}{l}\text { L antigen family, } \\
\text { member } 3\end{array}$ & $\mathrm{Xq} 28$ & $\mathrm{XLR}$ & $\begin{array}{l}\text { Galloway-Mowat-Syndrom } \\
\text { Typ 2: syndromales SRNS (early } \\
\text { onset), Mikrozephalie, ZNS-An- } \\
\text { omalien, faziale Dysmorphien }\end{array}$ & 301006 & FSGS, DMS & Selten \\
\hline OSGEP & 610107 & $\begin{array}{l}\text { O-sialoglyco- } \\
\text { protein endopep- } \\
\text { tidase }\end{array}$ & $14 q 11.2$ & AR & $\begin{array}{l}\text { Galloway-Mowat-Syndrom Typ } \\
\text { 3: syndromales SRNS (early } \\
\text { onset), Mikrozephalie, ZNS-An- } \\
\text { omalien, faziale Dysmorphien }\end{array}$ & 617729 & FSGS, DMS & Selten \\
\hline TP53RK & 608679 & $\begin{array}{l}\text { TP53 regulating } \\
\text { kinase }\end{array}$ & $20 q 13.12$ & $\mathrm{AR}$ & $\begin{array}{l}\text { Galloway-Mowat-Syndrom Typ } \\
\text { 4: syndromales SRNS (early } \\
\text { onset), Mikrozephalie, ZNS-An- } \\
\text { omalien, faziale Dysmorphien }\end{array}$ & 617730 & FSGS, DMS & Selten \\
\hline
\end{tabular}


Tab. 2 (Fortsetzung)

\begin{tabular}{|c|c|c|c|c|c|c|c|c|}
\hline Gen & $\begin{array}{l}\text { Gen } \\
\text { MIM \# }\end{array}$ & Protein & Genort & $\begin{array}{l}\text { Verer- } \\
\text { bungs- } \\
\text { modus }\end{array}$ & Phänotyp & $\begin{array}{l}\text { Phänotyp } \\
\text { MIM \# } \\
\text { (sofern } \\
\text { vorhanden) }\end{array}$ & $\begin{array}{l}\text { Nieren- } \\
\text { histologie }\end{array}$ & $\begin{array}{l}\text { Häufig- } \\
\text { keit }\end{array}$ \\
\hline TPRKB & 608680 & $\begin{array}{l}\text { TP53 regulating } \\
\text { kinase binding } \\
\text { protein }\end{array}$ & $2 \mathrm{p} 13.1$ & $\mathrm{AR}$ & $\begin{array}{l}\text { Galloway-Mowat-Syndrom Typ } \\
\text { 5: syndromales SRNS (early } \\
\text { onset), Mikrozephalie, ZNS Ano- } \\
\text { malien, faziale Dysmorphien }\end{array}$ & 617731 & FSGS, DMS & Selten \\
\hline WT1 & 607102 & $\begin{array}{l}\text { Wilms' tumor } \\
\text { protein } 1\end{array}$ & $11 \mathrm{p} 13$ & $A D$ & $\begin{array}{l}\text { CNS bis SRNS (early onset) oder } \\
\text { syndromal: Denys-Drash-Syn- } \\
\text { drom und Frasier-Syndrom }\end{array}$ & $\begin{array}{l}256370 \text { bzw. } \\
194080 \text { bzw. } \\
136680\end{array}$ & DMS, FSGS & $\begin{array}{l}\text { Häufig } \\
\text { (CNS) }\end{array}$ \\
\hline \multicolumn{9}{|c|}{ Zytoskelett- und Membranproteine } \\
\hline ACTN4 & 604638 & a-Actinin 4 & $19 q 13.2$ & $A D$ & $\begin{array}{l}\text { SRNS (variabel, early bis late } \\
\text { onset) }\end{array}$ & 603278 & FSGS & Moderat \\
\hline ARHGAP24 & 610586 & $\begin{array}{l}\text { Rho GTPase-ac- } \\
\text { tivating protein } \\
24\end{array}$ & $4 q 21.2-q 21.3$ & $A D$ & SRNS (variable onset) & - & FSGS & Selten \\
\hline ARHGDIA & 601925 & $\begin{array}{l}\text { Rho GDP disso- } \\
\text { ciation inhibitor } \\
\text { alpha }\end{array}$ & $17 q 25.3$ & $A R$ & $\begin{array}{l}\text { Syndromal CNS bis SRNS (early } \\
\text { onset), Entwicklungsverzöge- } \\
\text { rung (+ Epilepsie, + Blindheit) }\end{array}$ & 615244 & FSGS, DMS & Selten \\
\hline CUBN & 602997 & Cubilin & $10 \mathrm{p} 13$ & $A R$ & $\begin{array}{l}\text { Megaloblastäre Anämie SRNS } \\
\text { (Imerslund-Gräsbeck-Erkran- } \\
\text { kung) }\end{array}$ & 261100 & FSGS & Selten \\
\hline EMP2 & 602334 & $\begin{array}{l}\text { Epithelial mem- } \\
\text { brane protein } \\
2\end{array}$ & $16 p 13.13$ & $\mathrm{AR}$ & SSNS oder SRNS (early onset) & 615861 & MC & Selten \\
\hline INF2 & 610982 & Inverted formin 2 & $14 q 32.33$ & $A D$ & $\begin{array}{l}\text { SRNS isoliert (late on- } \\
\text { set) oder syndromal: } \\
\text { SRNS + Charcot-Marie-Tooth- } \\
\text { Krankheit (N-terminale Varian- } \\
\text { ten in Exon } 2 \text { und 3) }\end{array}$ & $\begin{array}{l}613237 \text { bzw. } \\
614455\end{array}$ & FSGS & Moderat \\
\hline KANK1 & 607704 & $\begin{array}{l}\text { Kidney ankyrin } \\
\text { repeat-containing } \\
\text { protein } 1\end{array}$ & $9 p 24.3$ & $A R$ & SSNS & 612900 & MC & Selten \\
\hline KANK2 & 614610 & $\begin{array}{l}\text { Kidney ankyrin } \\
\text { repeat-containing } \\
\text { protein } 2\end{array}$ & 19p13.2 & $\mathrm{AR}$ & SSNS bis SDNS & 617783 & MC & Selten \\
\hline KANK4 & 614612 & $\begin{array}{l}\text { Kidney ankyrin } \\
\text { repeat-containing } \\
\text { protein } 4\end{array}$ & $1 \mathrm{p} 31.3$ & $\mathrm{AR}$ & SRNS & - & FSGS & Selten \\
\hline$M A G I 2$ & 606382 & $\begin{array}{l}\text { Membrane asso- } \\
\text { ciated guanylate } \\
\text { kinase, inverted } 2\end{array}$ & $7 q 21.11$ & $\mathrm{AR}$ & CNS bis SRNS (early onset) & 617609 & MC & Selten \\
\hline MYO1E & 601479 & Myosin 1E & $15 q 22.2$ & $A R$ & SRNS (early onset) & 614131 & FSGS & Selten \\
\hline MYH9 & 160775 & $\begin{array}{l}\text { Myosin heavy } \\
\text { chain } 9 \text {, } \\
\text { non-muscle }\end{array}$ & $22 q 12.3$ & $A D$ & $\begin{array}{l}\text { MYH9-assoziierte Erkran- } \\
\text { kungen, SRNS syndromal: } \\
\text { Makrothrombozytopenie, } \\
\text { Hörstörung }\end{array}$ & 155100 & FSGS & Selten \\
\hline PTPRO & 600579 & $\begin{array}{l}\text { Protein-tyrosine } \\
\text { phosphatase } \\
\text { receptor type } 0\end{array}$ & $12 \mathrm{p} 12.3$ & $\mathrm{AR}$ & SRNS (early onset) & 614196 & FSGS, MC & Selten \\
\hline \multicolumn{9}{|c|}{ GBM-assoziierte Proteine } \\
\hline COL4A3 & 120070 & $\begin{array}{l}\text { Type IV collagen } \\
\text { a3 }\end{array}$ & $2 q 36.3$ & $A R, A D$ & Alport-Syndrom, TBMN & 203780 & FSGS & Häufig \\
\hline COL4A4 & 120131 & $\begin{array}{l}\text { Type IV collagen } \\
\text { a4 }\end{array}$ & $2 q 36.3$ & $A R, A D$ & Alport-Syndrom, TBMN & 203780 & FSGS & Häufig \\
\hline COL4A5 & 303630 & $\begin{array}{l}\text { Type IV collagen } \\
\text { a5 }\end{array}$ & Xq22.3 & $\mathrm{XLD}$ & Alport-Syndrom & 301050 & FSGS & Häufig \\
\hline
\end{tabular}




\begin{tabular}{|c|c|c|c|c|c|c|c|c|}
\hline Gen & $\begin{array}{l}\text { Gen } \\
\text { MIM \# }\end{array}$ & Protein & Genort & $\begin{array}{l}\text { Verer- } \\
\text { bungs- } \\
\text { modus }\end{array}$ & Phänotyp & $\begin{array}{l}\text { Phänotyp } \\
\text { MIM \# } \\
\text { (sofern } \\
\text { vorhanden) }\end{array}$ & $\begin{array}{l}\text { Nieren- } \\
\text { histologie }\end{array}$ & $\begin{array}{l}\text { Häufig- } \\
\text { keit }\end{array}$ \\
\hline ITGA3 & 605025 & Integrin a3 & $17 q 21.33$ & AR & $\begin{array}{l}\text { CNS bis SRNS (early onset), } \\
\text { Epidermolysis bullosa, } \\
\text { interstitielle Lungenkrankheit }\end{array}$ & 614748 & FSGS & Selten \\
\hline ITGB4 & 147557 & Integrin $\beta 4$ & $17 q 25.1$ & $A R$ & $\begin{array}{l}\text { CNS, SRNS, Epidermolysis } \\
\text { bullosa, interstitielle Lungen- } \\
\text { krankheit }\end{array}$ & - & FSGS & $\begin{array}{l}\text { Sehr } \\
\text { selten }\end{array}$ \\
\hline$\angle A M B 2$ & 150325 & Laminin beta- 2 & $3 p 21.31$ & $A R$ & $\begin{array}{l}\text { SRNS } \pm \text { Augenbefunde } \\
\text { (earyl onset), syndromal: } \\
\text { Pierson-Syndrom (Mikrokorie) }\end{array}$ & $\begin{array}{l}614199 \text { bzw. } \\
609049\end{array}$ & FSGS, DMS & Moderat \\
\hline \multicolumn{9}{|c|}{ Mitochondriale Proteine } \\
\hline $\begin{array}{l}\text { ADCK4 } \\
\text { (COQ8B) }\end{array}$ & 615567 & $\begin{array}{l}\text { AarF domain con- } \\
\text { taining kinase } \\
4\end{array}$ & $19 q 13.2$ & $\mathrm{AR}$ & $\begin{array}{l}\text { Meist nicht syndromales SRNS } \\
\text { (juvenile onset), evtl. Effekt } \\
\text { Coenzym Q10-Supplementation }\end{array}$ & 615573 & FSGS & $\begin{array}{l}\text { Selten- } \\
\text { moderat }\end{array}$ \\
\hline COQ2 & 609825 & Coenzyme Q2 & $\begin{array}{l}4 q 21.22- \\
q 21.23\end{array}$ & $A R$ & $\begin{array}{l}\text { Coenzym Q10-Mangel, syn- } \\
\text { dromales SRNS (early onset; } \\
\text { + variable extrarenale Sympto- } \\
\text { me) }\end{array}$ & 607426 & FSGS & Selten \\
\hline COQ6 & 614647 & Coenzyme Q6 & $14 q 24.3$ & $A R$ & $\begin{array}{l}\text { Coenzym Q10-Mangel, syn- } \\
\text { dromales SRNS mit Innenohr- } \\
\text { schwerhörigkeit (early onset) }\end{array}$ & 614650 & FSGS, DMS & Seltem \\
\hline \multicolumn{9}{|c|}{ Stoffwechselerkrankungen/Andere } \\
\hline SGPL1 & 603729 & $\begin{array}{l}\text { Sphingosine-1- } \\
\text { phosphate lyase }\end{array}$ & $10 q 22.1$ & $A R$ & $\begin{array}{l}\text { CNS bis SRNS (early onset), } \\
\text { Nebenniereninsuffizienz, ZNS- } \\
\text { Beteiligung, Entwicklungsver- } \\
\text { zögerung, Hypotonie, Haut } \\
\text { (Ichthiosis, Hyperpigmentation) }\end{array}$ & 617575 & FSGS & Selten \\
\hline DGKE & 601440 & $\begin{array}{l}\text { Diacylglycerol } \\
\text { kinase epsilon }\end{array}$ & $17 q 22$ & AR & $\begin{array}{l}\text { SRNS (early onset) oder aHUS } \\
\text { innerhalb des ersten Lebensjah- } \\
\text { res }\end{array}$ & 615008 & MGTM & Selten \\
\hline CLCN5 & 300008 & $\begin{array}{l}\text { Chloride channel } \\
5\end{array}$ & Xp11.23 & XLR & $\begin{array}{l}\text { Dent-Erkrankung, selten Ma- } \\
\text { nifestation als nephrotisches } \\
\text { Syndrom }\end{array}$ & 308990 & $\begin{array}{l}\text { Fokale Glo- } \\
\text { meruloskle- } \\
\text { rose }\end{array}$ & Selten \\
\hline \multicolumn{9}{|c|}{ FSGS-Risikofaktor für Afroamerikaner } \\
\hline APOL1 & 603743 & Apolipoprotein L1 & $22 q 22.11$ & G1, G2 Allele & (Suszeptibilität für) SRNS & 612551 & FSGS & $\begin{array}{l}\text { Sehr } \\
\text { häufig }\end{array}$ \\
\hline
\end{tabular}

\section{Genetische Ursachen für das SRNS}

Beim SRNS kann je nach Studie und Zahl der untersuchten Gene in 30 bis ca. $50 \%$ der Fälle eine hereditäre Ursache nachgewiesen werden, bei Patienten mit einer kongenitalen Form (CNS) sogar bei bis zu $97 \%$ [20, 22-24]. Studien bzgl. molekulargenetischer Ursachen bei erwachsenen Patienten sind zwar bisher nur eingeschränkt verfügbar, weisen jedoch auch in dieser Patientenkohorte auf eine nicht unerhebliche Prävalenz hereditärer Ursachen hin [22,24]. Auch wenn in diesem Patientenkollektiv der Anteil sekundärer Formen höher und aufgrund von Begleiterkrankungen eine klinische Charakterisierung häufig erschwert ist, so sollte dennoch in Abwesenheit einer klaren Erkrankungsursache auch hier immer eine hereditäre Genese erwogen werden.

Durch Anwendung moderner Hochdurchsatzverfahren wie „next generation sequencing“ (NGS) konnten in den vergangenen Jahren mehr als 50 Gene identi- fiziert werden, die mit einem SRNS/FSGS assoziiert sind (•Tab. 2). Viele dieser Gene kodieren für podozytäre Proteine [25, 26], daher wird das SRNS/FSGS-Spektrum auch zu den sog. Podozytopathien gezählt. Im Jahr 1998 konnten Varianten in NPHS1 mit dem kongenitalen NS vom finnischen Typ assoziiert werden [27]. In den darauffolgenden Jahren wurden weitere zahlreiche podozytäre Proteine sowohl für pädiatrische wie auch für adulte Formen des SRNS identifiziert. Bei der kongenitalen und infantilen Form finden 


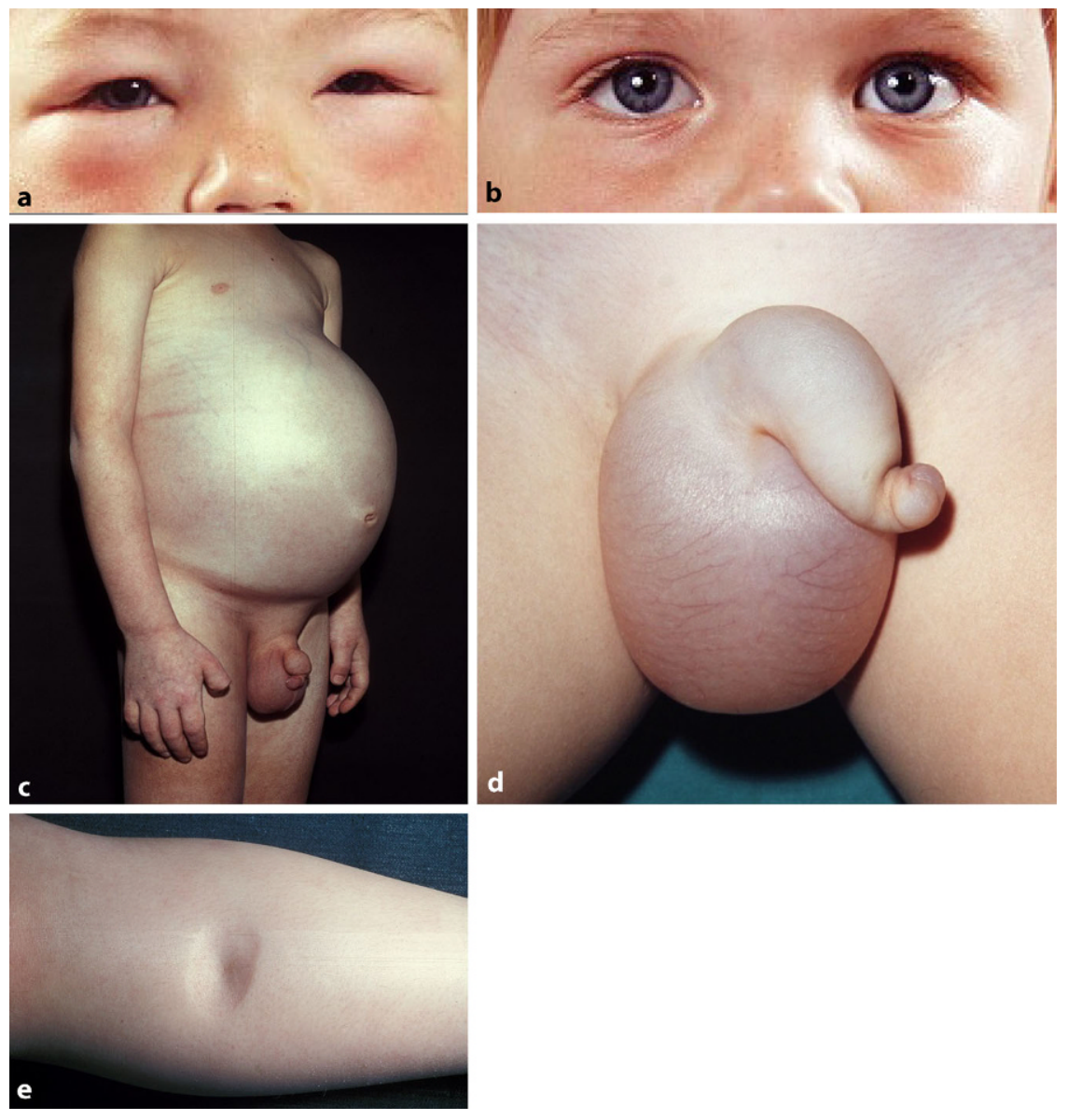

Abb. 1 ॥ Kind mit nephrotischem Syndrom. a vor Therapiebeginn, b 6 Monate nach Beendigung der Glukokortikoidtherapie und ohne Rezidiv, c Aszites beim nephrotischen Syndrom, d Skrotalödem beim nephrotischen Syndrom, e Unterschenkelödem bei nephrotischem Syndrom (aus [21])

sich bei bis zu $85 \%$ der Fälle kausale Varianten in den Genen NPHS1, NPHS2, $L A M B 2$ und WT1. Bei den später manifesten und/oder langsamer progredienten adulten Fällen werden Varianten in den Genen INF2, TRPC6, ACTN4, PAX2, $L M X 1 B$ und $C D 2 A P$ gehäuft beobachtet $[22,28,29]$. Während autosomal-rezessive Formen des SRNS meist bei pädiatrischen Patienten beobachtet werden (Ausnahme hier: spezifische NPHS2-Varianten) $[30,31]$, sind autosomal-dominante Formen durch einen allgemein sehr viel variableren Erkrankungsbeginn/-verlauf in der Kindheit bis ins Erwachsenenalter gekennzeichnet [25].

Neben der meist isolierten Form des SRNS werden auch syndromale Formen mit extrarenaler Symptomatik beobachtet. Hier seien beispielhaft der Pseudohermaphroditismus masculinus und Wilms-Tumor bei Varianten im WT1Gen (bei Vollbild des Denys-Drash-Syn- droms), die Mikrokorie bei Varianten im LAMB2-Gen (Pierson-Syndrom), die Skelettbeteiligung und Immundefizienz bei immuno-ossärer Dysplasie nach Schimke (SIOD) oder auch die Mikrozephalie und Entwicklungsverzögerung bei Varianten u.a. im WDR73Gen (Galloway-Mowat-Syndrom und KEOPS-Komplex) genannt [32-35].

Im Jahr 2011 konnten zudem erstmals Varianten in COQ6 als Ursache für eine mitochondriale Form des SRNS identifiziert werden. Hierdurch kommt es zu Störungen in der Coenzym Q10-Biosynthese mit dem klinischen Bild eines frühmanifesten SRNS mit sensorineuraler Schwerhörigkeit [36, 37]. Inzwischen konnten Varianten in weiteren an die Coenzym Q10-Biosynthese gekoppelten Genen (z. B. COQ2, ADCK4) identifiziert werden. Die Symptomatik dieser Patienten ist durch extrarenale Manifestationen wie z.B. Enzephalopathie, Epilepsie und
Kardiomyopathie gekennzeichnet [22, 37-40]. Durch Supplementierung von Coenzym Q10 wurde bereits bei einigen Patienten zumindest eine Remission der Proteinurie erzielt [41, 42].

\section{Pathogenese des SRNS}

Wie bereits oben erwähnt, kodieren die betroffenen Gene überwiegend für Proteine, die wichtig für die Entwicklung und den strukturellen Aufbau der Podozyten in den Glomeruli sind. Es konnte gezeigt werden, dass die veränderten Proteine verschiedenste zelluläre Strukturen und Signalkaskaden der Podozyten und benachbarter Strukturen betreffen (• Abb. 2; [43]). Nephrin und Podocin sind hierbei als Hauptbestandteile des Schlitzdiaphragmas an dessen Strukturaufbau und der Weiterleitung intrazellulärer Signale beteiligt $[44,45]$. CD2AP und a-Actinin 4 (ACTN4) dienen der Verlinkung von Schlitzdiaphragma und podozytärem Zytoskelett, CD2AP ist zudem in das intrazelluläre Trafficking involviert [46, 47]. Varianten in INF2, ACTN4 und MYO1E führen zur Destabilisierung des podozytären Zytoskeletts [48, 49], Varianten in KANK2, KANK4, ARHGAP24 und ARHGDIA beeinflussen über den RHOGTPase-Signalweg den AktinfilamentTurnover [2, 50, 51]. ITGA3 als Adhäsionsprotein, LAMB2 als Komponente der extrazellulären Matrix sowie weitere Proteine wie z.B. WT1 und LMX1B als Transkriptionsfaktoren sind in die Bindung der podozytären Fußfortsätze an die glomeruläre Basalmembran oder die Podozytendifferenzierung involviert [1, 32, 52-57]. Es besteht eine große Überlappung hinsichtlich Phänotyp und Biopsiebefund zu Patienten mit COL4A3, COL4A4 und COL4A5 assoziiertem Alport-Syndrom (siehe Beitrag "Genetische Ursachen und Therapie beim Alport-Syndrom") [58, 59].

\section{Wiederauftreten einer Protein- urie nach Nierentransplantation}

Für die genetischen und auch die vielen nicht hereditären Formen des SRNS stellt die Nierentransplantation oft die einzig kausale Therapieoption mit all- 


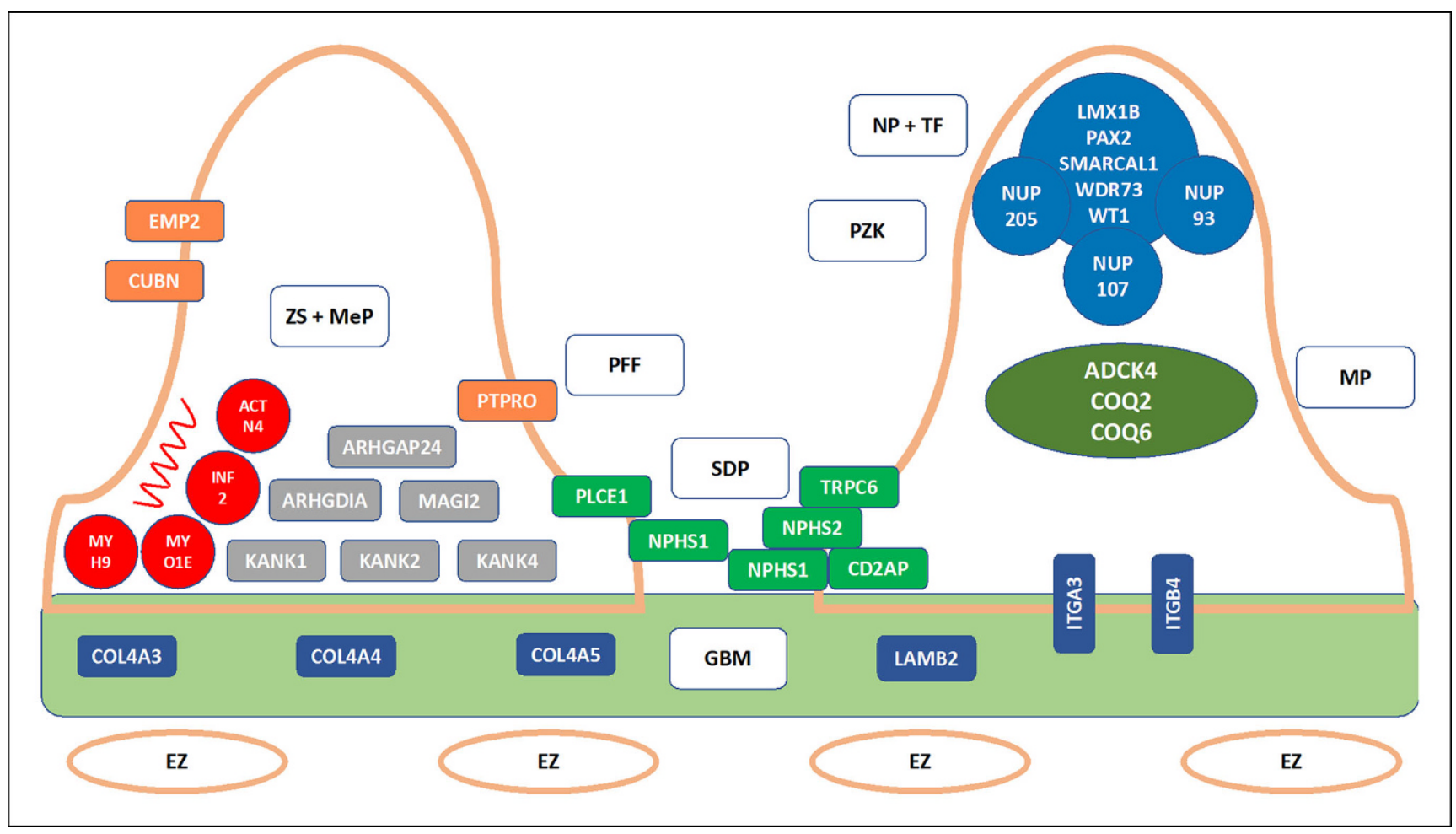

Abb. 2 \ Auswahl an SRNS-assoziierten Proteinen und deren Lokalisation im Podozyten und den angrenzenden Strukturen. EZ Endothelzelle, GBM glomeruläre Basalmembran, MP mitochondriale Proteine, NP + TF nukleäre Proteine und Transkriptionsfaktoren, PFF Podozyten-Fußfortsatz, PZK Podozyten-Zellkörper, SDP Schlitzdiaphragmaproteine, ZS + MeP Zytoskelett- und Membranproteine

gemein sehr guten Behandlungserfolgen dar. Nach Transplantation entwickeln Patienten aber nicht selten eine (milde) Proteinurie, deren Ursache von der chronischen Transplantatabstoßung über eine Rekurrenz der FSGS im Transplantat bis hin zu nephrotoxischen Medikamenteneffekten reichen kann.

Eine schwere Proteinurie kann sich nach Nierentransplantation bei nicht hereditärer Genese des SRNS/FSGS in bis zu $40 \%$ der Fälle innerhalb von Minuten bis Tagen entwickeln und wird als FSGSRekurrenz bezeichnet. Die Ursachen hierfür sind größtenteils unbekannt. Die Rolle des löslichen Urokinase-Rezeptors (suPAR) bleibt Gegenstand kontroverser Diskussionen.

Das Risiko einer Rekurrenz bei genetischen Formen ist allgemein viel geringer, aber bei Patienten mit trunkierenden Varianten in Nephrin (v.a. Patienten homozygot für die Fin-majorVariante c.121_22delCA) [60] und seltener auch bei trunkierenden Varianten in Podocin [61] kann es antikörpervermittelt zur Rekurrenz des NS nach Trans- plantation kommen. Auch bei Patienten mit Alport-Syndrom wird nach Nierentransplantation in ca. 2-5\% der Fälle das Auftreten einer anti-GBM-Nephritis beschrieben [62].

\section{Medikamentöse Behandlung des SRNS}

Die Behandlung der Komplikationen des NS im Allgemeinen sowie die Therapie des SSNS sind nicht Gegenstand dieses Beitrags. Es wird im Folgenden daher lediglich auf die spezifische und immunsuppressive Therapie des SRNS im Kindes- und Erwachsenenalter eingegangen.

\section{Kindesalter}

Das idiopathische SRNS mit histologischem Nachweis einer FSGS hat eine verbesserte Prognose, wenn langfristig mit Cyclosporin A therapiert wird [63]. Cyclosporin A zeigt neben dem immunsuppressiven einen direkten antiproteinurischen Effekt. Ein häufig verwendetes Therapieschema für das SRNS beinhal- tet Cyclosporin A in einer Dosis von $150-200 \mathrm{mg} / \mathrm{m}^{2} \mathrm{KOF} \times$ Tag, initial kombiniert mit Prednison in den ersten $6 \mathrm{Mo}-$ naten. Der Kalzineurin-Inhibitor Tacrolimus ist ebenso erfolgreich bei FSGS eingesetzt worden [64]. Patienten mit SRNS profitieren nicht von einer Cyclophosphamidtherapie [65]; in einzelnen Fällen ist die Wirksamkeit von MycophenolatMofetil (MMF) und Rituximab auch bei SRNS belegt.

Bei Nachweis einer monogenetischen Form des NS ist in der Regel keine weitere immunsuppressive Therapie indiziert. Einzelne Patienten sind jedoch durch eine Therapie mit Cyclosporin A in Teilremission gekommen [66]. Bei Nichtansprechen sollte die Therapie aber unbedingt beendet werden, um toxische Effekte $\mathrm{zu}$ vermeiden.

Neben immunsuppressiven Maßnahmen ist die Behandlung mit „Angiotensin-converting-enzyme" (ACE)Inhibitoren bzw. AngiotensinrezeptorAntagonisten Basistherapie bei Kindern mit SRNS, da sie antihypertensiv wirken, die Proteinurie reduzieren und 
die Progression einer Niereninsuffizienz bremsen. Bei Nichtansprechen auf eine Immunsuppression (z. B. bei genetischen Formen) kann u. U. eine rein antiproteinurische Therapie mit diesen Substanzen angezeigt sein [21].

Eine therapeutische Herausforderung ist die Therapie des kongenitalen NS, dem meist ein genetischer Hintergrund eigen ist und das nicht auf eine immunsuppressive Therapie anspricht. Die Therapie ist daher symptomatisch.

\section{Erwachsenenalter}

Im Unterschied zu Kindern zeigen sich bei Erwachsenen deutlich schlechtere Ansprechraten auf die initiale Glukokortikoidtherapie [15] und bereits eine partielle Remission gilt als Therapieerfolg [14-17]. Bei steroid-abhängigen bzw. -resistenten Verlaufsformen im Erwachsenenalter wird primär die Behandlung mit $3-5 \mathrm{mg} / \mathrm{kg} /$ Tag Cyclosporin A (aufgeteilt auf 2 Dosen pro Tag) für mindestens 4 bis 6 Monate mit oder ohne niedrig dosierte Glukokortikoide vorgeschlagen [16, 67-73]. Alternativ kann dabei die Gabe von Tacrolimus erwogen werden. Im Falle einer partiellen oder kompletten Remission sollte die Behandlung für mindestens 12 Monate fortgeführt werden, bevor eine langsame Reduktion der Dosis über Monate erfolgen kann. Patienten, die eine Cyclosporin A-Therapie nicht tolerieren bzw. hierauf nicht ansprechen, können alternativ mit MMF und Hochdosis-Dexamethason behandelt werden [74-78]. Hierzu zählen auch Patienten mit ausgeprägtem vaskulären Risikoprofil sowie ausgeprägter renaler Fibrosierung bzw. fortgeschrittener Niereninsuffizienz. Rituximab stellt darüber hinaus eine mögliche Alternative bei Patienten mit steroid-abhängigem SRNS dar [79-81].

Neben der primär immunsuppressiven Therapie ist auch bei Erwachsenen die Behandlung mit ACE-Inhibitoren bzw. Angiotensinrezeptor-Antagonisten Teil der Basistherapie - auch wenn normotensive Blutdruckwerte vorliegen [82, 83].

\section{Diagnostische Tools}

\section{Nierenbiopsie}

\section{Kindesalter}

Die Erstmanifestation eines idiopathischen NS ist keine Indikation zur Nierenbiopsie. Liegen jedoch folgende untypische klinische Befunde vor, besteht eine Indikation zur Nierenbiopsie und meist (mit Ausnahme sekundärer Formen) auch zur genetischen Testung.

Alter bei Erstmanifestation $<12$ Monate oder $>$ ( 8 bis) 10 Jahre:

- Makrohämaturie, ausgeprägte arterielle Hypertonie,

- erniedrigte Komplementfaktoren im Serum (C3),

- nicht prärenal bedingte akute Niereninsuffizienz,

- schleichender Beginn über Monate und

- Verdacht auf eine sekundäre Form des NS (z.B. im Rahmen einer Systemerkrankung: systemischer Lupus erythematodes, SchönleinHenoch-Purpura).

Auch das fehlende primäre Ansprechen des NS auf Glukokortikoidgaben (Steroidresistenz) stellt eine Biopsie-Indikation dar. Patienten mit häufigen Rezidiven ("frequent relapser") werden nach individueller Entscheidung und in Abhängigkeit vom Verlauf vor einer zytostatischen/ immunsuppressiven Therapie oder nach Nichtansprechen einer solchen nierenbiopsiert.

\section{Erwachsenenalter}

Im Gegensatz zu Kindern besteht bei Erwachsenen vor dem Hintergrund der vielfältigen Differentialdiagnosen des NS bereits bei Erstmanifestation eine Indikation zur Nierenbiopsie. Bei fehlendem Therapieansprechen bzw. häufigen Rezidiven sind nach individueller Entscheidung Rebiopsien angezeigt, um die initiale Diagnose zu erhärten bzw. zu revidieren.

Bei folgenden Patienten kann die Durchführung einer Rebiopsie jedoch diskutiert und evtl. hintangestellt werden:

- Patienten mit einem langjährigem Diabetes mellitus mit dem typischen
Verlauf einer zunächst moderaten Albuminurie, die langsam zum Vollbild eines NS fortschreitet,

- Patienten mit entsprechender Medikamenteneinnahme und zeitlichem Bezug zum Auftreten des NS, z. B. NSAR, Bisphosphonate, Penicillamin, Gold, Lithium,

- Patienten mit bekanntem Malignom und

- Patienten mit ausgeprägter Adipositas.

\section{Molekulargenetische Untersuchungsmethoden}

Aufgrund der klinischen Variabilität und der genetischen Heterogenität des SRNS ist es außerhalb der CNS-Altersgruppe aufgrund des Erkrankungsspektrums in Abwesenheit spezifischer klinischer Symptome häufig schwer, bei Patienten das Gen zu benennen, in dem die ursächlichen Varianten vorliegen. Einzelgen-Untersuchungen mittels SangerSequenzierung spielen daher außerhalb o.g. Altersgruppe inzwischen nur noch eine untergeordnete Rolle (sind aber mitunter noch die schnellste Möglichkeit zur definitiven Diagnose eines CNS mit hoher Trefferrate in nur drei Genen: NPHS1, NPHS2 und WT1) und werden außerhalb einer gezielten Diagnostik (Untersuchung auf eine bekannte familiäre Variante) zunehmend weniger eingesetzt. Aufgrund der verbesserten molekulargenetischen Diagnostik unter Einsatz der NGS-Technologien wie z.B. Gen-Panel-Diagnostik, Exom- oder Genom-Analyse ist heutzutage in vielen Fällen eine klinische und genetische Einordnung möglich und damit ggf. eine Möglichkeit der optimierten und individualisierten Therapie. Während genetische Untersuchungen einen klaren Stellenwert in der pädiatrischen Patientenkohorte mit NS haben, werden diese bei erwachsenen Patienten immer noch sehr zurückhaltend veranlasst.

\section{Ausblick}

Die molekulargenetische Untersuchung im Rahmen eines humangenetischen Beratungsgespräches und damit die Rolle des Humangenetikers spielen eine 
zentrale Rolle bei der Behandlung von pädiatrischen und adulten Patienten mit SRNS, um weitere klinische Schritte bzgl. invasiver Diagnostik, medikamentöser Therapie und Transplantation $\mathrm{zu}$ planen sowie ein mögliches Wiederholungsrisiko bei Verwandten anzugeben. Eine interdisziplinäre Zusammenarbeit von (Kinder-)Nephrologen und Humangenetikern sollte daher zukünftig von beiden Seiten weiter forciert werden.

\section{Fazit für die Praxis}

- Das SRNS wird im Kindes- und Erwachsenenalter beobachtet und kann isoliert oder im Rahmen einer syndromalen Erkrankung auftreten.

- Patienten mit SRNS, bei denen keine hereditäre Ursache oder Varianten in Nephrin nachgewiesen werden, haben nach Nierentransplantation ein erhöhtes Rekurrenzrisiko in der Transplantatniere.

- Molekulargenetische Untersuchungen sollten auch bei erwachsenen Patienten mit SRNS erwogen werden, da auch bei dieser Patientenkohorte bei Nachweis einer hereditären Ursache Aussagen über ein mögliches Wiederholungsrisiko gemacht werden können.

- Die Therapie des SRNS bei Erwachsenen beruht auf einer dualen Immunsuppression mit KalzineurinInhibitoren bzw. Mycophenolat und niedrig dosierten Glukokortikoiden.

\section{Korrespondenzadresse}

PD Dr. Julia Hoefele

Institut für Humangenetik,

Klinikum rechts der Isar,

Technische Universität München

Trogerstr. 32, 81675 München, Deutschland julia.hoefele@tum.de

\section{Dr. Bodo B. Beck}

Institut für Humangenetik, Uniklinik Köln Kerpener Str. 34, 50937 Köln, Deutschland bodo.beck@uk-koeln.de

Prof. Dr. Lutz T. Weber

Klinik und Poliklinik für Kinder- und Jugendmedizin, Uniklinik Köln Kerpener Str. 62, 50937 Köln, Deutschland lutz.weber@uk-koeln.de

Prof. Dr. Paul Brinkkötter

Klinik II für Innere Medizin, Uniklinik Köln Kerpener Str. 62, 50937 Köln, Deutschland paul.brinkkoetter@uk-koeln.de

\section{Einhaltung ethischer Richtlinien}

Interessenkonflikt. B.B. Beck, L.T. Weber und P. Brinkkötter werden durch die KFO 329 „Disease pathways in podocyte injury - from molecular mechanisms to individualized treatment options" von der DFG und J. Hoefele durch die Gesellschaft für Pädiatrische Nephrologie gefördert. Weitere Informationen unter https://www.podocyte.org/ und https://gpn.de/.

Dieser Beitrag beinhaltet keine von den Autoren durchgeführten Studien an Menschen oder Tieren.

Open Access. Dieser Artikel wird unter der Creative Commons Namensnennung 4.0 International Lizenz (http://creativecommons.org/licenses/by/4.0/deed. de) veröffentlicht, welche die Nutzung, Vervielfältigung, Bearbeitung, Verbreitung und Wiedergabe in jeglichem Medium und Format erlaubt, sofern Sie den/die ursprünglichen Autor(en) und die Quelle ordnungsgemäßnennen, einen Linkzur Creative Commons Lizenz beifügen und angeben, ob Änderungen vorgenommen wurden.

\section{Literatur}

1. Gee HY, Ashraf $S$, Wan $X$, Vega-Warner $V_{t}$ Esteve-Rudd J, Lovric S, Fang H, Hurd TW, Sadowski CE, Allen SJ, Otto EA, Korkmaz E, Washburn J, Levy S, Williams DS, Bakkaloglu SA, Zolotnitskaya A, Ozaltin F, Zhou W, Hildebrandt F (2014) Mutations in EMP2 cause childhood-onset nephrotic syndrome. Am J Hum Genet 94:884-890

2. Gee HY, Zhang F, Ashraf S, Kohl S, Sadowski CE, Vega-Warner V, Zhou W, Lovric S, Fang H, Nettleton M, Zhu JY, Hoefele J, Weber LT, Podracka L, Boor A, Fehrenbach $\mathrm{H}$, Innis JW, Washburn J, Levy S, Lifton RP, Otto EA, Han Z, Hildebrandt F (2015) KANK deficiency leads to podocyte dysfunction and nephrotic syndrome. J Clin Invest 125:2375-2384
3. Rivera F, Lopez-Gomez JM, Perez-Garcia R (2004) Clinicopathologic correlations of renal pathology in Spain. Kidney Int 66:898-904

4. Haas M, Meehan SM, Karrison TG, Spargo BH (1997) Changing etiologies of unexplained adult nephrotic syndrome: a comparison of renal biopsy findings from 1976-1979 and 1995-1997. Am J Kidney Dis 30:621-631

5. Braden GL, Mulhern JG, O'Shea MH, Nash SV, Ucci AA Jr., Germain MJ (2000) Changing incidence of glomerular diseases in adults. Am J Kidney Dis 35:878-883

6. Simon P, Ramee MP, Boulahrouz R, Stanescu C, Charasse C, Ang KS, Leonetti F, Cam G, Laruelle E, Autuly V, Rioux N (2004) Epidemiologic data of primary glomerular diseases in western France. Kidney Int 66:905-908

7. Malafronte $P$, Mastroianni-Kirsztajn $G$, Betonico GN, Romao JE Jr., Alves MA, Carvalho MF, Viera Neto OM, Cadaval RA, Bergamo RR, Woronik V, Sens YA, Marrocos MS, Barros RT (2006) Paulista Registry of glomerulonephritis: 5-year data report. Nephrol Dial Transplant 21:3098-3105

8. Bahiense-Oliveira M, Saldanha LB, Mota EL, Penna DO, Barros RT, Romao-Junior JE (2004) Primary glomerular diseases in Brazil (1979-1999): is the frequency of focal and segmental glomerulosclerosis increasing? Clin Nephrol 61:90-97

9. Gesualdo L, Di Palma AM, Morrone LF, Strippoli GF, Schena FP, Italian Immunopathology Group ISoN (2004) The Italian experience of the national registry of renal biopsies. Kidney Int 66:890-894

10. Heaf J (2004) The Danish Renal Biopsy Register. Kidney Int 66:895-897

11. Braun N, Schweisfurth $A$, Lohofener $C$, Lange C, Grundemann C, Kundt G, Grone HJ (2011) Epidemiology of glomerulonephritis in Northern Germany. Int Urol Nephrol 43:1117-1126

12. Genovese G, Friedman DJ, Ross MD, Lecordier L, Uzureau P, Freedman BI, Bowden DW, Langefeld CD, Oleksyk TK, Uscinski Knob AL, Bernhardy AJ, Hicks PJ, Nelson GW, Vanhollebeke B, Winkler CA, Kopp JB, Pays E, Pollak MR (2010) Association of trypanolytic ApoL1 variants with kidney disease in African Americans. Science 329:841-845

13. Querfeld U, Dötsch J, Gellermann J, Hoyer $P$, Kemper M, Latta K, Tönshoff B, Weber LT, Rascher W (2017) Diagnostik und Therapie des idipathischen nephrotischen Syndroms im Kindesalter. Monatsschr Kinderheilkd 11:997-1003

14. Rydel JJ, Korbet SM, Borok RZ, Schwartz MM (1995) Focal segmental glomerular sclerosis in adults: presentation, course, and response to treatment. Am J Kidney Dis 25:534-542

15. Troyanov S, Wall CA, Miller JA, Scholey JW, Cattran DC, Toronto Glomerulonephritis Registry $\mathrm{G}$ (2005) Focal and segmental glomerulosclerosis: definition and relevance of a partial remission. JAm Soc Nephrol 16:1061-1068

16. Cattran DC, Appel GB, Hebert LA, Hunsicker LG, Pohl MA, Hoy WE, Maxwell DR, Kunis CL (1999) A randomized trial of cyclosporine in patients with steroid-resistant focal segmental glomerulosclerosis. North America Nephrotic Syndrome Study Group. Kidney Int 56:2220-2226

17. Ponticelli C, Villa M, Banfi G, Cesana B, Pozzi C, Pani A, Passerini P, Farina M, Grassi C, Baroli A (1999) Can prolonged treatment improve the prognosis in adults with focal segmental glomerulosclerosis? Am J Kidney Dis 34:618-625

18. Gipson DS, Massengill SF, Yao L, Nagaraj S, Smoyer WE, Mahan JD, Wigfall D, Miles P, Powell L, Lin JJ, Trachtman H, Greenbaum LA (2009) Management 
of childhood onset nephrotic syndrome. Pediatrics 124:747-757

19. Citak A, Emre S, Sairin A, Bilge I, Nayir A (2000) Hemostatic problems and thromboembolic complications in nephrotic children. Pediatr Nephrol 14:138-142

20. Buscher AK, Beck BB, Melk A, Hoefele J, Kranz $B$, Bamborschke D, Baig S, Lange-Sperandio B, Jungraithmayr T, Weber LT, Kemper MJ, Tonshoff $B$, Hoyer PF, Konrad M, Weber S, Pediatric Nephrology GA (2016) Rapid Response to Cyclosporin A and Favorable Renal Outcome in Nongenetic Versus Genetic Steroid-Resistant Nephrotic Syndrome. Clin J Am Soc Nephrol 11:245-253

21. Weber LT, Pohl M, Büscher AK, Weber S, Riedl M, Licht C, Amann K (2017) Glomeruläre Erkrankungen. In: Dötsch J, Weber LT (Hrsg) Nierenerkrankungen im Kindesalter. Springer, Heidelberg

22. Sadowski CE, Lovric S, Ashraf S, Pabst WL, Gee HY, Kohl S, Engelmann S, Vega-Warner V, Fang $\mathrm{H}$, Halbritter J, Somers MJ, Tan W, Shril S, Fessi I, Lifton RP, Bockenhauer D, El-Desoky S, Kari JA, Zenker M, Kemper MJ, Mueller D, Fathy HM, Soliman NA, GroupSS, HildebrandtF(2015) A single-genecause in $29.5 \%$ of cases of steroid-resistant nephrotic syndrome. J Am Soc Nephrol 26:1279-1289

23. Hinkes BG, Mucha B, Vlangos CN, Gbadegesin R, Liu J, Hasselbacher K, Hangan D, Ozaltin F, Zenker $M$, Hildebrandt $F$ (2007) Nephrotic syndrome in the first year of life: two thirds of cases are caused by mutations in 4 genes (NPHS1, NPHS2, WT1, and LAMB2). Pediatrics 119:e907-e919

24. Santin S, Bullich G, Tazon-Vega B, Garcia-Maset R, Gimenez I, Silva I, Ruiz P, Ballarin J, Torra R, Ars E (2011) Clinical utility of genetic testing in children and adults with steroid-resistant nephrotic syndrome. Clin J Am Soc Nephrol 6:1139-1148

25. Warejko JK, Tan W, Daga A, Schapiro D, Lawson JA, Shril S, Lovric S, Ashraf S, Rao J, Hermle T, JobstSchwan T, Widmeier E, Majmundar AJ, Schneider $\mathrm{R}$, Gee HY, Schmidt JM, Vivante A, van der Ven AT, Ityel $H$, Chen J, Sadowski CE, Kohl S, Pabst WL, Nakayama M, Somers MJG, Rodig NM, Daouk G, Baum M, Stein DR, Ferguson MA, Traum AZ, Soliman NA, Kari JA, El Desoky S, Fathy H, Zenker M, Bakkaloglu SA, Muller D, Noyan A, Ozaltin F, Cadnapaphornchai MA, Hashmi S, Hopcian J, Kopp JB, Benador N, Bockenhauer D, Bogdanovic R, Stajic $\mathrm{N}$, Chernin G, Ettenger R, Fehrenbach $\mathrm{H}$, Kemper M, Munarriz RL, Podracka L, Buscher R, Serdaroglu E, Tasic V, Mane S, Lifton RP, Braun DA, Hildebrandt F (2018) Whole exome sequencing of patients with steroid-resistant Nephrotic syndrome. Clin J Am Soc Nephrol 13:53-62

26. Preston R, Stuart HM, Lennon R (2017) Genetic testing in steroid-resistant nephrotic syndrome: why, who, when and how? Pediatr Nephrol. https:// doi.org/10.1007/s00467-017-3838-6

27. Kestila M, Lenkkeri U, Mannikko M, Lamerdin J, McCready P, Putaala H, Ruotsalainen V, Morita $T$, Nissinen $M$, Herva $R$, Kashtan $C E$, Peltonen L, Holmberg C, Olsen A, Tryggvason K (1998) Positionally cloned gene for a novel glomerular protein-nephrin-is mutated in congenital nephrotic syndrome. Mol Cell 1:575-582

28. Buscher AK, Konrad M, Nagel M, Witzke O, Kribben A, Hoyer PF, Weber S (2012) Mutations in podocyte genes are a rare cause of primary FSGS associated with ESRD in adult patients. Clin Nephrol 78:47-53

29. Barua M, Stellacci E, Stella L, Weins A, Genovese G, Muto V, Caputo V, Toka HR, Charoonratana VT, Tartaglia M, Pollak MR (2014) Mutations in PAX2 associate with adult-onset FSGS. J Am Soc Nephrol 25:1942-1953

30. Kerti A, Csohany R, Szabo A, Arkossy O, Sallay $P$, Moriniere V, Vega-Warner V, Nyiro G, Lakatos O, Szabo T, Lipska BS, Schaefer F, Antignac C, Reusz G, Tulassay T, Tory K (2013) NPHS2 p.V290M mutation in late-onset steroid-resistant nephrotic syndrome. Pediatr Nephrol 28:751-757

31. Tory K, Menyhard DK, Woerner S, Nevo F, Gribouval O, Kerti A, Straner P, Arrondel C, Huynh Cong E, Tulassay T, Mollet G, Perczel A, Antignac C (2014) Mutation-dependent recessive inheritance of NPHS2-associated steroid-resistant nephrotic syndrome. Nat Genet 46:299-304

32. Pelletier J, Bruening W, Kashtan CE, Mauer SM, Manivel JC, Striegel JE, Houghton DC, Junien C, HabibR, Fouser Let al (1991) Germline mutations in the Wilms' tumor suppressor gene are associated with abnormal urogenital development in DenysDrash syndrome. Cell 67:437-447

33. Zenker M, Aigner T, Wendler O, Tralau T, Muntefering $\mathrm{H}$, Fenski R, PitzS, Schumacher V, Royer-Pokora B, Wuhl E, Cochat P, Bouvier R, Kraus C, Mark K, Madlon H, Dotsch J, Rascher W, Maruniak-Chudek I, Lennert T, Neumann LM, Reis A (2004) Human laminin beta2 deficiency causes congenital nephrosis with mesangial sclerosis and distinct eye abnormalities. Hum Mol Genet 13:2625-2632

34. Colin E, Huynh Cong E, Mollet G, Guichet A, Gribouval O, Arrondel C, Boyer O, Daniel L, Gubler MC, Ekinci Z, Tsimaratos M, Chabrol B, Boddaert $\mathrm{N}$, Verloes A, Chevrollier A, Gueguen N, DesquiretDumas V, Ferre M, Procaccio V, Richard L, Funalot B, Moncla A, Bonneau D, Antignac C (2014) Lossof-function mutations in WDR73 are responsible for microcephaly and steroid-resistant nephrotic syndrome: Galloway-Mowat syndrome. Am J Hum Genet 95:637-648

35. Braun DA, Rao J, Mollet G, Schapiro D, Daugeron MC, Tan W, Gribouval O, Boyer O, Revy P, JobstSchwan T, Schmidt JM, Lawson JA, Schanze D, Ashraf S, Ullmann JFP, Hoogstraten CA, Boddaert $\mathrm{N}$, Collinet B, Martin G, Liger D, Lovric S, Furlano M, Guerrera IC, Sanchez-Ferras O, Hu JF, Boschat AC, Sanquer S, Menten B, Vergult S, De Rocker N, Airik M, Hermle T, Shril S, Widmeier E, Gee HY, Choi WI, Sadowski CE, Pabst WL, Warejko JK, Daga A, Basta T, Matejas V, Scharmann K, Kienast SD, Behnam B, Beeson B, Begtrup A, Bruce M, Ch'ng GS, Lin SP, Chang JH, Chen CH, Cho MT, Gaffney PM, Gipson PE, Hsu CH, Kari JA, Ke YY, KiralyBorri C, Lai WM, Lemyre E, Littlejohn RO, Masri A, Moghtaderi M, Nakamura K, Ozaltin F, Praet M, Prasad C, Prytula A, Roeder ER, Rump P, Schnur RE, Shiihara T, Sinha MD, Soliman NA, Soulami K, Sweetser DA, Tsai WH, Tsai JD, Topaloglu R, Vester U, Viskochil DH, Vatanavicharn N, Waxler JL, Wierenga KJ, WolfMTF, Wong SN, Leidel SA, Truglio G, Dedon PC, Poduri A, Mane S, Lifton RP, Bouchard M, Kannu P, Chitayat D, Magen D, Callewaert B, van Tilbeurgh H, Zenker M, Antignac C, Hildebrandt F (2017) Mutations in KEOPS-complex genes cause nephrotic syndrome with primary microcephaly. Nat Genet 49:1529-1538

36. Heeringa SF, Chernin G, Chaki M, Zhou W, Sloan AJ, Ji Z, Xie LX, Salviati L, Hurd TW, Vega-Warner V, Killen PD, Raphael Y, Ashraf S, Ovunc B, Schoeb DS McLaughlin HM, Airik R, Vlangos CN, Gbadegesin $R$, Hinkes $B$, Saisawat $P$, Trevisson $E$, Doimo $M$, Casarin A, Pertegato V, Giorgi G, Prokisch $H$, Rotig A, Nurnberg G, Becker C, Wang S, Ozaltin F, Topaloglu R, Bakkaloglu A, Bakkaloglu SA, Muller D, Beissert A, Mir S, Berdeli A, Varpizen S, Zenker M, Matejas V, Santos-Ocana C, Navas
P, Kusakabe T, Kispert A, Akman S, Soliman NA, Krick S, Mundel P, Reiser J, Nurnberg P, Clarke CF, Wiggins RC, Faul C, Hildebrandt F (2011) COQ6 mutations in human patients produce nephrotic syndrome with sensorineural deafness. J Clin Invest 121:2013-2024

37. Park E, Ahn YH, Kang HG, Yoo KH, Won NH, Lee KB, Moon KC, Seong MW, Gwon TR, Park SS, Cheong HI (2017) COQ6 mutations in children with steroidresistant focal segmental Glomerulosclerosis and sensorineural hearing loss. Am J Kidney Dis 70:139-144

38. Ashraf S, Gee HY, Woerner S, Xie LX, Vega-Warner V, Lovric S, Fang $H$, Song $X$, Cattran DC, Avila-Casado C, Paterson AD, Nitschke P, Bole-Feysot C, Cochat P, Esteve-Rudd J, Haberberger B, Allen SJ, Zhou W, Airik R, Otto EA, Barua M, Al-Hamed MH, Kari JA, Evans J, Bierzynska A, Saleem MA, Bockenhauer D, Kleta R, El Desoky S, Hacihamdioglu DO, Gok F, Washburn J, Wiggins RC, Choi M, Lifton RP, Levy S, Han Z, Salviati L, Prokisch H, Williams DS, Pollak M, Clarke CF, Pei Y, Antignac C, Hildebrandt F (2013) ADCK4 mutations promote steroid-resistant nephrotic syndrome through $\mathrm{CoQ} 10$ biosynthesis disruption. JClin Invest 123:5179-5189

39. Korkmaz E, Lipska-Zietkiewicz BS, Boyer O, Gribouval O, Fourrage C, Tabatabaei M, Schnaidt S, Gucer S, Kaymaz F, Arici M, Dinckan A, Mir $S$, Bayazit AK, Emre S, Balat A, Rees L, Shroff R, Bergmann C, Mourani C, Antignac C, Ozaltin F, Schaefer F, PodoNet C (2016) ADCK4-Associated Glomerulopathy Causes Adolescence-Onset FSGS J Am Soc Nephrol 27:63-68

40. Diomedi-Camassei F, DiGiandomenicoS, Santorelli FM, Caridi G, Piemonte F, Montini G, Ghiggeri GM, Murer L, Barisoni L, Pastore A, Muda AO, Valente ML, Bertini E, Emma F (2007) COQ2 nephropathy: a newly described inherited mitochondriopathy with primary renal involvement. J Am Soc Nephrol 18:2773-2780

41. Montini G, Malaventura C, Salviati L (2008) Early coenzyme Q10 supplementation in primary coenzyme Q10 deficiency. NEngl J Med 358:2849-2850

42. Atmaca M, Gulhan B, Korkmaz E, Inozu M, Soylemezoglu O, Candan C, Bayazit AK, Elmaci AM, Parmaksiz G, Duzova A, Besbas N, Topaloglu $R$, Ozaltin $F$ (2017) Follow-up results of patients with ADCK4 mutations and the efficacy of CoQ10 treatment. Pediatr Nephrol 32:1369-1375

43. Wiggins RC (2007) The spectrum of podocytopathies: a unifying view of glomerular diseases. Kidney Int 71:1205-1214

44. Tryggvason K (1999) Unraveling the mechanisms of glomerular ultrafiltration: nephrin, a key component of the slit diaphragm. J Am Soc Nephrol 10:2440-2445

45. Schwarz K, Simons M, Reiser J, Saleem MA, Faul C, Kriz W, Shaw AS, Holzman LB, Mundel P (2001) Podocin, a raft-associated component of the glomerular slit diaphragm, interacts with CD2AP and nephrin. JClin Invest 108:1621-1629

46. Kaplan JM, Kim SH, North KN, Rennke H, Correia $L A$, Tong $H Q$, Mathis BJ, Rodriguez-Perez JC, Allen PG, Beggs AH, Pollak MR (2000) Mutations in ACTN4, encoding alpha-actinin-4, cause familial focal segmental glomerulosclerosis. Nat Genet 24:251-256

47. Shih NY, Li J, Karpitskii V, Nguyen A, Dustin ML, Kanagawa O, Miner JH, Shaw AS (1999) Congenital nephrotic syndrome in mice lacking CD2-associated protein. Science 286:312-315

48. Brown EJ, Schlondorff JS, Becker DJ, Tsukaguchi $\mathrm{H}$, Tonna SJ, Uscinski AL, Higgs HN, Henderson JM, Pollak MR (2010) Mutations in the formin gene 
INF2 cause focal segmental glomerulosclerosis. Nat Genet 42:72-76

49. Gbadegesin RA, Hall G, Adeyemo A, Hanke N, Tossidou I, Burchette J, Wu G, Homstad A, Sparks MA, Gomez J, Jiang R, Alonso A, Lavin P, Conlon P, Korstanje R, Stander MC, Shamsan G, Barua M, Spurney R, Singhal PC, Kopp JB, Haller H, Howell D, Pollak MR, Shaw AS, Schiffer M, Winn MP (2014) Mutations in the gene that encodes the F-actin binding protein anillin cause FSGS. J Am Soc Nephrol 25:1991-2002

50. GeeHY, SaisawatP, AshrafS, HurdTW, Vega-Warne V, Fang H, Beck BB, Gribouval O, Zhou W, Diaz KA, Natarajan $S$, Wiggins RC, Lovric $S$, Chernin $G$, SchoebDS, OvuncB, Frishberg Y, Soliman NA, Fathy HM, Goebel H, Hoefele J, Weber LT, Innis JW, Faul C, Han Z, Washburn J, Antignac C, Levy S, Otto EA, Hildebrandt F (2013) ARHGDIA mutations cause nephrotic syndrome via defective RHO GTPase signaling. J Clin Invest 123:3243-3253

51. Akilesh S, Suleiman H, Yu H, Stander MC, Lavin P, Gbadegesin R, Antignac C, Pollak M, Kopp JB, Winn MP, Shaw AS (2011) Arhgap24 inactivates Rac1 in mouse podocytes, and a mutant form is associated with familial focal segmental glomerulosclerosis. JClin Invest 121:4127-4137

52. Nicolaou N, Margadant C, Kevelam SH, Lilien MR, Oosterveld MJ, Kreft M, van Eerde AM, Pfundt R, Terhal PA, van der Zwaag B, Nikkels PG, Sachs N, Goldschmeding R, Knoers NV, Renkema KY, Sonnenberg A (2012) Gain of glycosylation in integrin alpha3 causes lung disease and nephrotic syndrome. J Clin Invest 122:4375-4387

53. Winn MP, Conlon PJ, Lynn KL, Farrington MK Creazzo T, Hawkins AF, Daskalakis N, Kwan SY, Ebersviller S, Burchette $\mathrm{JL}$, Pericak-Vance MA Howell DN, Vance JM, Rosenberg PB (2005) A mutation in the TRPC6 cation channel causes familial focal segmental glomerulosclerosis. Science 308:1801-1804

54. Dreyer SD, Zhou G, Baldini A, Winterpacht A, Zabe B, Cole W, Johnson RL, Lee B (1998) Mutations in LMX1B cause abnormal skeletal patterning and renal dysplasia in nail patella syndrome. Nat Genet 19:47-50

55. Hall G, Gbadegesin RA, Lavin P, Wu G, Liu Y, Oh EC, Wang L, Spurney RF, Eckel J, Lindsey T, Homstad A, Malone AF, Phelan PJ, Shaw A, Howell DN, Conlon PJ, Katsanis N, Winn MP (2015) A novel missense mutation of Wilms' Tumor 1 causes autosomal dominantFSGS.J Am Soc Nephrol 26:831-843

56. Riehle M, Buscher AK, Gohlke BO, Kassmann M, Kolatsi-Joannou M, Brasen JH, Nagel M, Becker JU, Winyard P, Hoyer PF, Preissner R, Krautwurst D, Gollasch M, Weber S, Harteneck C (2016) TRPC6 G757D Loss-of-Function Mutation Associates with FSGS. J Am Soc Nephrol 27:2771-2783

57. Weber S, Buscher AK, Hagmann H, Liebau MC, Heberle C, Ludwig M, Rath S, Alberer M, Beissert A, Zenker M, Hoyer PF, Konrad M, Klein HG, Hoefele $J$ (2016) Dealing with the incidental finding of secondary variants by the example of SRNS patients undergoing targeted next-generation sequencing. Pediatr Nephrol 31:73-81

58. Gast C, Pengelly RJ, Lyon M, Bunyan DJ, Seaby EG, Graham N, Venkat-Raman G, Ennis S (2016) Collagen (COL4A) mutations are the most frequent mutations underlying adult focal segmental glomerulosclerosis. Nephrol Dial Transplant 31:961-970

59. Malone AF, Phelan PJ, Hall G, CetincelikU, Homstad A, Alonso AS, Jiang R, Lindsey TB, Wu G, Sparks MA, Smith SR, Webb NJ, Kalra PA, Adeyemo AA, Shaw AS, Conlon PJ, Jennette JC, Howell DN,
Winn MP, Gbadegesin RA (2014) Rare hereditary COL4A3/COL4A4 variants may be mistaken for familial focal segmental glomerulosclerosis. Kidney Int 86:1253-1259

60. Kuusniemi AM, QvistE, Sun Y, Patrakka J, Ronnholm K, Karikoski R, Jalanko H (2007) Plasma exchange and retransplantation in recurrent nephrosis of patients with congenital nephrotic syndrome of the Finnish type (NPHS1). Transplantation 83:1316-1323

61. Weber S, Gribouval O, Esquivel EL, Moriniere V, Tete MJ, LegendreC, NiaudetP, AntignacC (2004) NPHS2 mutation analysis shows genetic heterogeneity of steroid-resistant nephrotic syndrome and low post-transplant recurrence. Kidney Int 66:571-579

62. Gillion V, Dahan K, Cosyns JP, Hilbert P, Jadoul M, Goffin E, Godefroid N, De Meyer M, Mourad M, Pirson Y, Kanaan N (2018) Genotype and Outcome After Kidney Transplantation in Alport Syndrome. Kidney Int Rep 3:652-660

63. Ehrich JH, Geerlings C, Zivicnjak M, Franke D Geerlings H, Gellermann J (2007) Steroid-resistant idiopathic childhood nephrosis: overdiagnosed and undertreated. Nephrol Dial Transplant 22:2183-2193

64. van Husen M, Kemper MJ (2011) New therapies in steroid-sensitive and steroid-resistant idiopathic nephrotic syndrome. Pediatr Nephrol 26:881-892

65. Plank C, Kalb V, Hinkes B, Hildebrandt F, Gefeller O, Rascher W (2008) Cyclosporin A is superior to cyclophosphamide in children with steroidresistant nephrotic syndrome-a randomized controlled multicentre trial by the Arbeitsgemeinschaft fur Padiatrische Nephrologie. Pediatr Nephrol 23:1483-1493

66. Buscher AK, Kranz B, Buscher R, Hildebrandt F, Dworniczak B, Pennekamp P, Kuwertz-Broking $\mathrm{E}_{\text {, }}$ Wingen AM, John U, Kemper M, Monnens L, Hoye PF, Weber S, Konrad M (2010) Immunosuppression and renal outcome in congenital and pediatric steroid-resistant nephrotic syndrome. Clin J Am Soc Nephrol 5:2075-2084

67. Meyrier A, Noel LH, Auriche P, Callard P (1994) Long-term renal tolerance of cyclosporin $A$ treatment in adult idiopathic nephrotic syndrome. Collaborative Group of the Societe de Nephrologie. Kidney Int 45:1446-1456

68. Niaudet $P$ (1994) Treatment of childhood steroidresistant idiopathic nephrosis with a combination of cyclosporine and prednisone. French Society of Pediatric Nephrology. J Pediatr 125:981-986

69. Lieberman KV, Tejani A (1996) A randomized double-blind placebo-controlled trial of cyclosporine in steroid-resistant idiopathic focal segmenta glomerulosclerosis in children. J Am Soc Nephrol 7:56-63

70. Heering $\mathrm{P}$, Braun $\mathrm{N}$, Mullejans $\mathrm{R}$, Ivens $\mathrm{K}$, Zauner I, Funfstuck R, Keller F, Kramer BK, Schollmeyer P, Risler T, Grabensee B, Collaborative Glomerulonephritis Study GG (2004) Cyclosporine $A$ and chlorambucil in the treatment of idiopathic focal segmental glomerulosclerosis. Am J Kidney Dis 43(10): 18

71. Burgess $E$ (1999) Management of focal segmenta glomerulosclerosis: evidence-based recommendations. Kidney Int Suppl 70:26-32

72. Korbet SM, Schwartz MM, Lewis EJ (1994) Primary focal segmental glomerulosclerosis: clinical course and response to therapy. Am J Kidney Dis 23:773-783

73. Ponticelli C, Rizzoni G, Edefonti A, Altieri P, RivoltaE, Rinaldi S, Ghio L, Lusvarghi E, Gusmano R, Locatelli F et al (1993) A randomized trial of cyclosporine in steroid-resistant idiopathic nephrotic syndrome Kidney Int 43:1377-1384

74. Choi MJ, Eustace JA, Gimenez LF, Atta MG, ScheelPJ, Sothinathan R, Briggs WA (2002) Mycophenolate mofetil treatment for primary glomerular diseases. Kidney Int 61:1098-1114

75. Day CJ, Cockwell P, Lipkin GW, Savage CO, Howie AJ, Adu D (2002) Mycophenolate mofetil in the treatment of resistant idiopathic nephrotic syndrome. Nephrol Dial Transplant 17:2011-2013

76. Montane B, Abitbol C, Chandar J, Strauss J, Zilleruelo G (2003) Novel therapy of focal glomerulosclerosis with mycophenolate and angiotensin blockade. Pediatr Nephrol 18:772-777

77. Cattran DC, Wang MM, Appel G, Matalon A, Briggs W (2004) Mycophenolate mofetil in the treatment of focal segmental glomerulosclerosis. Clin Nephrol 62:405-411

78. Gipson DS, Trachtman H, Kaskel FJ, Greene TH Radeva MK, Gassman JJ, Moxey-Mims MM, Hogg RJ, Watkins SL, Fine RN, Hogan SL, Middleton JP, Vehaskari VM, Flynn PA, Powell LM, Vento SM, McMahan JL, Siegel N, D'Agati VD, Friedman AL (2011) Clinical trial of focal segmental glomerulosclerosis in children and young adults. Kidney Int 80:868-878

79. Kronbichler A, Konig P, Busch M, Wolf G, Maye G, Rudnicki M (2013) Rituximab in adult patients with multi-relapsing/steroid-dependent minimal change disease and focal segmental glomerulosclerosis: a report of 5 cases. Wien Klin Wochenschr 125:328-333

80. Ochi A, Takei T, Nakayama K, Iwasaki C, Kamei D, Tsuruta Y, Shimizu A, Shiohira S, Moriyama T, Itabashi M, Mochizuki T, Uchida K, Tsuchiya K, Hattori M, Nitta K (2012) Rituximab treatment for adult patients with focal segmental glomerulosclerosis. Intern Med 51:759-762

81. Fernandez-Fresnedo G, Segarra A, Gonzalez E, AlexandruS, Delgado R, Ramos N, Egido J, Praga M, Grupo de Trabajo de Enfermedades Glomerulares de la Sociedad Espanola de Nefrologia (GLOSEN) (2009) Rituximab treatment of adult patients with steroid-resistant focal segmental glomerulosclerosis. Clin J Am Soc Nephrol 4:1317-1323

82. Korbet SM (2003) Angiotensin antagonists and steroids in the treatment of focal segmental glomerulosclerosis. Semin Nephrol 23:219-228

83. Praga M, Hernandez E, Montoyo C, Andres A, Ruilope LM, Rodicio JL (1992) Long-term beneficial effects of angiotensin-converting enzyme inhibition in patients with nephrotic proteinuria. Am J Kidney Dis 20:240-248 